\title{
Effect of Nanoparticles on Wettability of Nanocoating on Carbon Steel
}

\author{
Norhasnidawani Johari, Noor Azlina Hassan, Norita Hassan, and Mohd Hanafi Ani
}

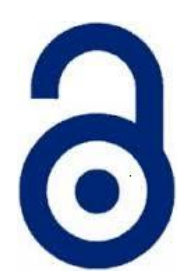

Received: 28 November 2016

Accepted: 15 December 2016

Published: 20 December 2016

Publisher: Deer Hill Publications

(c) 2016 The Author(s)

Creative Commons: CC BY 4.0

\begin{abstract}
Nanocoatings plays an important role in coating industry. The great potential of nanocoatings was studied due to an excellent adhesion strength and corrosion protection of carbon steel. Nanocoatings was formulated through copolymerization of epoxy resin with the incorporation of $\mathrm{Zinc} O$ Oxide $(\mathrm{ZnO})$ and Silica $\left(\mathrm{SiO}_{2}\right)$ nanoparticles. $\mathrm{ZnO}$ and $\mathrm{SiO}_{2}$ were synthesized using sol-gel technique. Epoxy acted as host while the nanoparticles incorporate as guest components. The performance of wetting ability with different medium was analysed using contact angle. Water medium showed the addition of $3 \mathrm{wt} \%$ of hybrid between $\mathrm{ZnO}$ and $\mathrm{SiO}_{2}$ was the best nanocoating to form hydrophobic surface and was also the best nanocoating surface to form hydrophilic surface with vacuum oil dropping. The contact angle was smaller than $90^{\circ}$ in oil dropping.
\end{abstract}

Keywords: Zinc Oxide ( $\mathrm{ZnO})$, Silica $\left(\mathrm{SiO}_{2}\right)$, Nanoparticles, Contact Angle, Nanocoating, Carbon steel

\section{INTRODUCTION}

Nanocoatings market is envisaged to grow over the next 5 to 10 years across all market segments. This is attributed to growing need for better facilities and advances in nanocoatings technology. This industry is segmented by type of future markets that includes anti-bacterial, anti-fouling, anti-fingerprint, easy to maintain and self-cleaning nanocoatings [1]. Potential applications such as self-cleaning increasing interest in wettability concerns. Wettability is one of the important characteristics that determine the properties of final coating [2].

The degree of wetting when a solid and liquid interact is determined by measurements of contact angle. Surface with low wettability shows the contact angles $\left(<90^{\circ}\right)$ while large contact angle is $\left(>90^{\circ}\right)$ corresponding to high wettability [3]. Steel is widely used for construction especially in heavy industries such as in the petrochemical, marine, and etc that exposed to corrosion [4].

Sol-gel hybrid coatings of organic and inorganic materials can combine the mechanical toughness and flexibility of organic components with the thermal stability and hardness of inorganic components [5]. Epoxy (organic) coating is a type of common organic coatings used to protect metal against corrosion. Research by Armelin [6] reported that the benzene rings in epoxy giving good properties such as resistance to chemical, good mechanical properties, thermal stability and good adhesion make it widely used for protective coatings.

The epoxy contains ring opening during curing time. The hydrophobic and hydrophilic group in epoxy structure increases the adhesion properties. The epoxy molecule is combined with a hardener material and effect crosslinking during curing or hardening [7]. $\mathrm{ZnO}$ is used as nanoparticles increased the adhesion and absorption of the UV radiation can stop solar degradation. The UV light is transform into vibration and heat [8]. The incorporation of silica nanoparticles provides better adhesion since nanoparticles acted denser and compact structure in the coating. The coating having good properties with solid and protective network layer when the nanoparticles are uniformly distributed throughout the coating. The nanoparticles function as elastomeric structure within the coating [9]. This research discussed on the wetting ability when deionised water and vacuum oil come into contact with the carbon steel.

\footnotetext{
J. Norhasnidawani, H. N. Azlina 凶, H. Norita, and M. H. Ani

Department of Manufacturing and Materials Engineering

International Islamic University Malaysia

PO Box 10, 50728 Kuala Lumpur, Malaysia

E-mail: noorazlina_hassan@iium.edu.my
}

Reference: J. Norhasnidawani, H. N. Azlina, H. Norita, and Hanafi Ani (2016). Effect of Nanoparticles on Wettability of Nanocoating on Carbon Steel. International Journal of Engineering Materials and Manufacture, 1(2), 71-74. 


\section{METHODOLOGY}

The nanoparticles was synthesized by using sol gel method. There were 18 pieces of carbon steels used in the study. The surfaces of samples were ground and polished with a manual hand grinder machine. The samples were then rinsed in distilled water and dried with acetone to remove traces of water. This step was conducted quickly to avoid premature corrosion. Brushing technique was used to coat the samples. Before coating, the epoxy was blend with hardener and stirred at 500rpm for 5 minutes, using overhead stirrer. Nanoparticles powder was poured right after and continuously stirred for another 5 minutes to obtain homogeneous mix. After mixing, the modified epoxy coating was then applied onto carbon steel coupons. The coupons were left to dry overnight in fume cupboard at room temperature. Then, the effect of nanoparticles on wetting ability was measured using contact angle. The conditions of testing are listed in Table 1.

\section{RESULTS AND DISCUSSION}

\subsection{Deionized Water Dropping}

There was attraction between the solid and liquid on the surface influenced by surface energy. Based on Figures 1 , deionized water drop on carbon steel surface showed that partial wetting occurred. This condition is known as hydrophobic or water hating. The contact angle of water droplet on surface is between $71^{\circ}$ to $77^{\circ}$. The contact angle of liquid drop is based on the adhesive forces between the liquid and the surface [9].

The adhesives force was repelled and a liquid drop minimizes its contact with the surface. It was called hydrophobic where the area of solid surface decreased. Incorporation of nanoparticles into coating increased the degree of contact angle. This showed that $\mathrm{ZnO}$ and $\mathrm{SiO}_{2}$ nanoparticles was effectively imparting hydrophobic properties to the steel surface and determining the corrosion behaviour of the surface. Foreign particles were also repelled from the coating surface due to high contact angle. It shows that the wetting energy is getting smaller and become more hydrophobic [10]. Figure 1 show micrograph images of water dropping on nanocoating surface. Addition of $3 w \mathrm{t} \% \mathrm{ZnO}+2 \mathrm{wt} \% \mathrm{SiO}_{2}$ (hybrid) was the best formulation of nanocoating to form hydrophobic surface with good work of adhesion. Table 2 summarized the contact angle behaviour on different surface of nanocoating through deionized water dropping analysis.

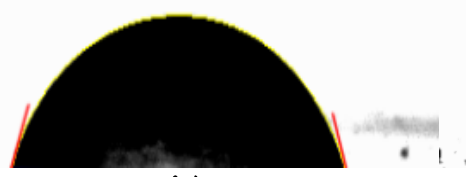

(a)

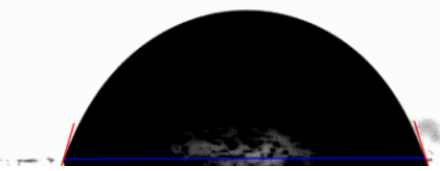

(d)

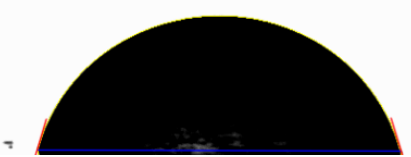

(g)

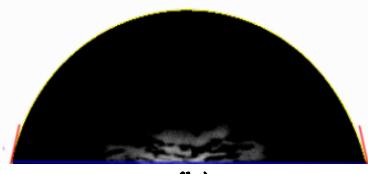

(b)

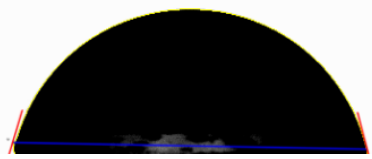

(e)

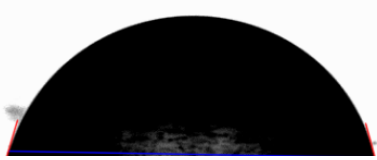

(h)

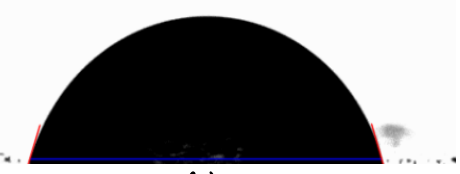

(c)

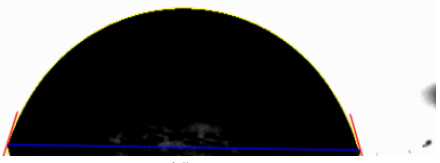

(f)

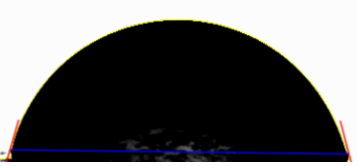

(i)

Figure 1: Micrograph images of water dropping on nanocoating: (a) Plain Epoxy; (b) $2 w t \% \mathrm{ZnO}$; (c) $3 w t \% \mathrm{ZnO}$; (d) $2 w t \% \mathrm{SiO}_{2}$; (e) $3 w t \% \mathrm{SiO}_{2}$; (f) $1 \mathrm{wt} \% \mathrm{ZnO}+4 \mathrm{wt} \% \mathrm{SiO}_{2}$; (g) $2 \mathrm{wt} \% \mathrm{ZnO}+3 \mathrm{wt} \% \mathrm{SiO}_{2}$; (h) $3 w t \% \mathrm{ZnO}+2 \mathrm{wt} \%$ $\mathrm{SiO}_{2}$; (i) $4 \mathrm{wt} \% \mathrm{ZnO}+1 \mathrm{wt} \% \mathrm{SiO}_{2}$

\subsection{Vacuum Oil Dropping}

Oil molecules have low surface tension and stronger attraction to the molecules of the solid surface. This shows that, the adhesive force is stronger than cohesive forces. Vacuum oil dropping onto carbon steel showed that there are strong adhesive forces on nanocoating surfaces due low surface tension and increases the area of solid surface contact [11]. This type of surface is called partial wetting or water loving. Incorporation of nanoparticles improved the ability of coatings and improved the adhesion between coating and substrate [12].

In the case of vacuum oil dropping analysis nanocoating allows liquids to spread on surface due to low surface tension. The contact angle is less than $90^{\circ}$, as shown in Figure 2, shows that the oil drop spreads out and wet the surface. Figure 2(h), exhibit the lowest contact angle among all due to strong adhesive forces. It showed that in marine applications, when there was attraction between surface and coatings, adding another layer of nanocoating was enough after certain period of time. Table 3 summarized the contact angle, wetting energy and work of addition on different surface of vacuum oil dropping. 
Table 1: Selected condition during contact angle testing

\begin{tabular}{lll}
\hline Properties (Unit) & Water & Oil \\
\hline Rec. Temperature $\left({ }^{\circ} \mathrm{C}\right)$ & 20 & 20 \\
Syringe Temperature $\left({ }^{\circ} \mathrm{C}\right)$ & 20 & 20 \\
Drop Volume $(\mu \mathrm{L})$ & 18.3 & 0.65 \\
Rec. Time & $05: 54.8$ & $53: 28: 4$ \\
Rec. Pos $X(\mathrm{~mm})$ & 0 & 0 \\
Rec. PosY $(\mathrm{mm})$ & 0 & 0 \\
\hline
\end{tabular}

Table 2: Contact Angle of Nanocoating (Water Drop)

\begin{tabular}{llll}
\hline $\begin{array}{l}\text { Surface } \\
(w+\%)\end{array}$ & $\begin{array}{l}\text { Contact Angle } \\
\text { (Degree) }\end{array}$ & $\begin{array}{l}\text { Wetting Energy } \\
(\mathrm{mN} / \mathrm{m})\end{array}$ & $\begin{array}{l}\text { Work of Adhesion } \\
(\mathrm{mN} / \mathrm{m})\end{array}$ \\
\hline Epoxy & 72.71 & 21.64 & 94.44 \\
$2 \mathrm{ZnO}($ single) & 77.96 & 15.18 & 87.98 \\
$3 \mathrm{ZnO}($ single) & 73.38 & 20.83 & 93.63 \\
$2 \mathrm{SiO}_{2}$ (single) & 73.05 & 21.23 & 94.03 \\
$3 \mathrm{SiO}_{2}($ single) & 75.31 & 18.46 & 91.26 \\
$1 \mathrm{ZnO}+4 \mathrm{SiO}_{2}$ (hybrid) & 73.58 & 20.57 & 93.38 \\
$2 \mathrm{ZnO}+3 \mathrm{SiO}_{2}$ (hybrid) & 74.88 & 18.99 & 91.79 \\
$3 \mathrm{ZnO}+2 \mathrm{SiO}_{2}$ (hybrid) & 75.71 & 17.98 & 90.78 \\
$4 \mathrm{ZnO}+1 \mathrm{SiO}_{2}$ (hybrid) & 75.86 & 17.78 & 90.58 \\
\hline
\end{tabular}

Table 3: Contact Angle of Nanocoating (Oil Drop)

\begin{tabular}{llll}
\hline $\begin{array}{l}\text { Surface } \\
(w t \%)\end{array}$ & $\begin{array}{l}\text { Contact Angle } \\
\text { (Degree) }\end{array}$ & $\begin{array}{l}\text { Wetting Energy } \\
(\mathrm{mN} / \mathrm{m})\end{array}$ & $\begin{array}{l}\text { Work of Adhesion } \\
(\mathrm{mN} / \mathrm{m})\end{array}$ \\
\hline Epoxy & 19.95 & 68.43 & 141.23 \\
$2 \mathrm{ZnO}$ (single) & 12.96 & 70.95 & 143.75 \\
$3 \mathrm{ZnO}$ (single) & 15.85 & 70.03 & 142.83 \\
$2 \mathrm{SiO}_{2}$ (single) & 14.12 & 70.60 & 143.40 \\
$3 \mathrm{SiO}_{2}($ single) & 19.43 & 68.65 & 141.45 \\
$1 \mathrm{ZnO}+4 \mathrm{SiO}_{2}$ (hybrid) & 12.76 & 71.00 & 143.80 \\
$2 \mathrm{ZnO}+3 \mathrm{SiO}_{2}$ (hybrid) & 13.17 & 70.89 & 143.69 \\
$3 \mathrm{ZnO}+2 \mathrm{SiO}_{2}$ (hybrid) & 11.51 & 71.34 & 144.14 \\
$4 \mathrm{ZnO}+1 \mathrm{SiO}_{2}$ (hybrid) & 12.87 & 70.97 & 143.77 \\
\hline
\end{tabular}

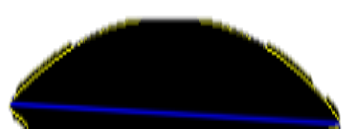

(a)

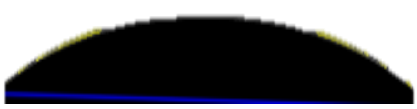

(d)

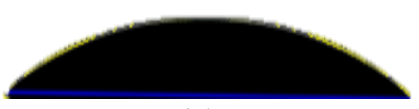

(g)

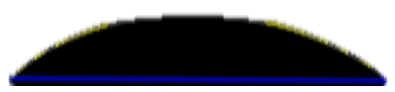

(b)

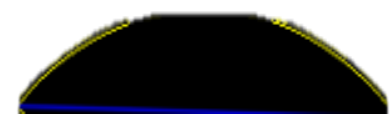

(e)

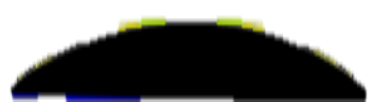

(h)

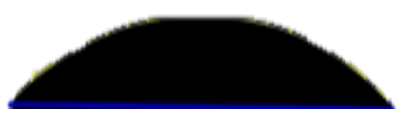

(c)

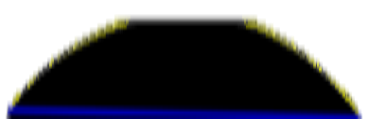

(f)

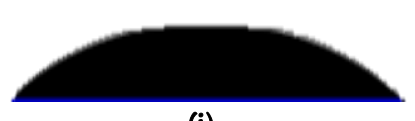

(i)

Figure 2: Micrograph images of vacuum oil dropping on nanocoatings: (a) Plain Epoxy; (b) 2wt\% $\mathrm{ZnO}$; (c) $3 w t \%$ $\mathrm{ZnO}$; (d) $2 w t \% \mathrm{SiO}_{2}$; (e) $3 w t \% \mathrm{SiO}_{2}$; (f) $1 w t \% \mathrm{ZnO}+4 w t \% \mathrm{SiO}_{2}$; (g) $2 w t \% \mathrm{ZnO}+3 w t \% \mathrm{SiO}_{2}$; (h) $3 w t \% \mathrm{ZnO}+2 w t \%$ $\mathrm{SiO}_{2}$; (i) $4 \mathrm{wt} \% \mathrm{ZnO}+1 \mathrm{wt} \% \mathrm{SiO}_{2}$ 


\section{CONCLUSIONS}

In this research study, adding nanoparticles into epoxy coating decreased the wetting energy and become more hydrophobic. Addition of $3 w t \% \mathrm{ZnO}+2 w_{t} \% \mathrm{SiO}_{2}$ (hybrid) was the best nanocoating surface to form hydrophobic surface for deionized water dropping. For vacuum oil dropping, adding nanoparticles allowed liquids to spread on surface. Nanoparticles increased the ability of nanocoatings. There was improvement in adhesion of coating and carbon steel as a substrate. Addition of $3 \mathrm{wt} \% \mathrm{ZnO}+2 \mathrm{wt} \% \mathrm{SiO}_{2}$ (hybrid) was the best nanocoating surface to form hydrophilic surface with vacuum oil dropping.

\section{ACKNOWLEDGEMENT}

The authors acknowledge Ministry of Higher Education (MOHE) for Research Grant FRGS13-077-125-0318 for funding this research activities. The authors are grateful to the Materials Department Laboratory where the experimental studies were conducted.

\section{REFERENCES}

1. Thomas (2013). Market Research Study on Nanocoatings. Retrieve from: http://marketpublishers.com.

2. Cabrera-Sierra, Sosa, E., Oropeza, M. T., \& Gonzalez, I. (2012). Electrochemical study on carbon corrosion process in alkaline sour media. Electrochimia Acta, 47(13-14), 2149-2158.

3. Armelin, E. (2011). Corrosion protection with polyaniline and polypyrole as anticorrosive additives for epoxy paint. Corrosion Science, 50(3), 721-728.

4. Tan, A. L. K., \& Soutar, A. M. (2008). Hybrid sol-gel coatings for corrosion protection of copper. Thin Solids Film, 516(16), 5706-5709.

5. Atik, M., \& Aegerter, M. A. (2009). Corrosion resistant sol-gel $\mathrm{ZrO}_{2}$ on stainless steel. Journal of Non-Crystalline Solids, 147-148, 236-241.

6. Shen, G. X., Chen, Y. C., Lin C.J., \& Scantleburry, D. (2012). Study on a hydrophobic nano $\mathrm{TiO}_{2}$ coating and its properties for corrosion protection of metals. Electrochimia Acta, 50(25-26), 5083-5089.

7. Shang, J., Flury, M., James, B. H., \& Richard, L. Zollars. (2008). Comparison of different methods to measure contact angles of soil colloids. Journal of Colloid and Interface Science, 328(2), 299-307.

8. Phan, H. T., Caney, N., Marty, P., Colasson, S., \& Gavillet, J. (2009). Surface wettability control by nanocoating: The effects on pool boiling heat transfer and nucleation mechanism. International Journal of Heat and Mass Transfer, 52(23-24), 5459-5471.

9. Zhai, L., Fevzi, C. C., Robert, E. C., \& Michael, F. R. (2004). Stable superhydrophobic coatings from polyelectrolyte multilayers. Nanoletters, 4(7), 1349-1353.

10. Shen, G. X., Chen, Y. C., Lin, L., Lin, C. J. \& Scantlebury, D. (2005). Study on a hydrophobic nano-TiO $2 \mathrm{Coating}$ and its properties for corrosion protection of metals. Electrochimica Acta, 50(25-26), 5083-5089.

11. Rosario, R., Gust, D., Antonio, A. G., Mark Hayes, J. L., Taraci, T. C., Dailey, J. W. \& Picraux, S. T. (2004). Lotus effect amplifies light-induced contact angle switching. Journal of Physical Chemistry B, 108(34), 12640-12642.

12. Steele, A., Bayer, I., \& Loth, E. (2009). Inherently superoleophobic nanocomposite coatings by spray atomization. Nanoletters, 9(1), 501-505. 